\title{
ESTUDO DA SECAGEM DE SILAGEM DE PESCADO EM SECADOR DE BANDEJA E LIOFILIZADOR
}

\author{
V. A. PEREIRA JUNIOR ${ }^{1}$, P. N. CRUZ ${ }^{1}$ e G. A. S. GOULART ${ }^{2}$ \\ ${ }^{1}$ Universidade Federal de Santa Catarina, Departamento de Engenharia Química e Engenharia de \\ Alimentos \\ ${ }^{2}$ Universidade Federal de Mato Grosso, Departamento de Engenharia de Alimentos \\ E-mail para contato: engenheiro.jr321@gmail.com
}

\begin{abstract}
RESUMO - Inicialmente foi produzida silagem de resíduos de pescados, em seguida promoveu-se a secagem do ensilado em secador de bandeja em diferentes temperaturas $\left(50^{\circ} \mathrm{C}\right.$ e $\left.60^{\circ} \mathrm{C}\right)$ e cargas de silagem $(\sim 48,8 \mathrm{~g}$ e $\sim 97,5 \mathrm{~g})$ aplicando planejamento experimental. Avaliou-se a composição centesimal antes e após a secagem. A composição centesimal da silagem in natura não apresentou discrepância quando comparada à literatura. $\mathrm{O} \mathrm{pH}$ final da silagem de pescado ficou próximo ao descrito pela literatura


centesimal da silagem seca em bandejas foram divergentes em relação à linearidade para a obtenção da variável resposta. O processo de liofilização apresentou-se como a melhor opção para minimizar as perdas de nutrientes. As curvas experimentais da secagem em bandeja apresentaram dois períodos distintos, sendo observado que a secagem ocorreu principalmente na primeira fase do período de taxa decrescente.
\end{abstract}

\section{INTRODUÇÃO}

Uma das maiores preocupações da indústria alimentícia, no cenário atual, encontra-se nos mecanismos de conservação dos alimentos. Com o objetivo de aumentar a vida útil dos produtos, e minimizar as alterações das características organolépticas e nutritivas, a indústria desenvolve novas técnicas para a conservação de alimentos e aprimoram-se as existentes. Essas técnicas asseguram o atendimento ao mercado consumidor durante todo o ano. Nesse contexto, avaliando a indústria pesqueira no Brasil, pouco se tem feito para aproveitar de forma sustentável a produção pesqueira capturada, tanto no segmento direcionado para exportação como no que se desenvolve no mercado interno. Esses resíduos provindos da piscicultura (cabeça, pele, espinhas e vísceras), podem chegar a $70 \%$ do peso inicial desses peixes, e são considerados matéria-prima de baixa qualidade, que na maioria dos casos, não são utilizados durante o processamento (Morais \& Martins, 1981) e quando usados adequadamente, podem constituir um aporte de alto valor biológico na nutrição animal e incentivo econômico para as indústrias que os produzem. Uma alternativa promissora é a recuperação das proteínas dos subprodutos de pescado. A viabilidade do reaproveitamento desse tipo de material no preparo de diversos produtos alimentícios, como o surimi, shumai, fishburger, salsichas e patês são apresentados por Venugopal \& Shahidi, (1995). Outra possibilidade para o uso desses subprodutos é a elaboração de produtos alimentícios desidratados da suspensão ou pasta de pescado. $\mathrm{O}$ método da 

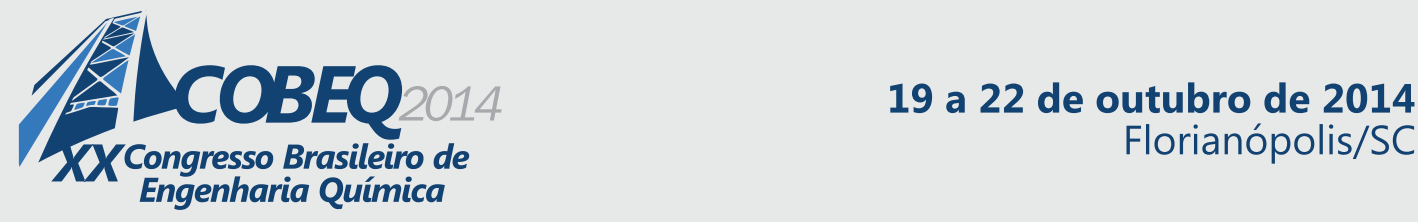

Florianópolis/SC

desidratação de produtos biológicos, como os de pescado e seus derivados, é demasiadamente usado na conservação considerando sua relação na melhoria da qualidade do produto e por minimizar seu potencial deteriorativo durante a armazenagem pois reduz a atividade de água, e consequentemente a ação microbiana e de reações enzimáticas no produto (Carvajal, 1998).

Dentre os métodos de secagem, existe a liofilização que é baseada na diminuição do teor de umidade em alimentos, a partir do congelamento e subsequente sublimação da água, sendo mais eficiente se comparado aos outros meios de desidratação. Desta forma, a relevância deste estudo se estabelece no processo de produção e obtenção do produto seco de silagem de pescado.

\section{MATERIAIS E MÉTODOS}

\subsection{Preparo da Suspensão}

Utilizou-se como matéria prima, o resíduo de pescado (cabeça e rabo de peixe bico-de-pato, Sorubim lima) coletado nos criatórios de peixes da cidade de Barra do Garças, sendo este pescado proveniente do vale do Araguaia, região compreendida entre os Estados de Goiás e de Mato Grosso, no Centro-Oeste do Brasil e cortada pelo Rio Araguaia. Em relação ao preparo da solução extratora, foi usado sais de fosfato monobásico $\left(\mathrm{Na}_{2} \mathrm{HPO}_{4}\right)$, fosfato dibásico $\left(\mathrm{NaH}_{2} \mathrm{PO}_{4}\right)$ e cloreto de sódio $(\mathrm{NaCl})$. O processo de produção da silagem de pescado ocorreu conforme a Figura 1.

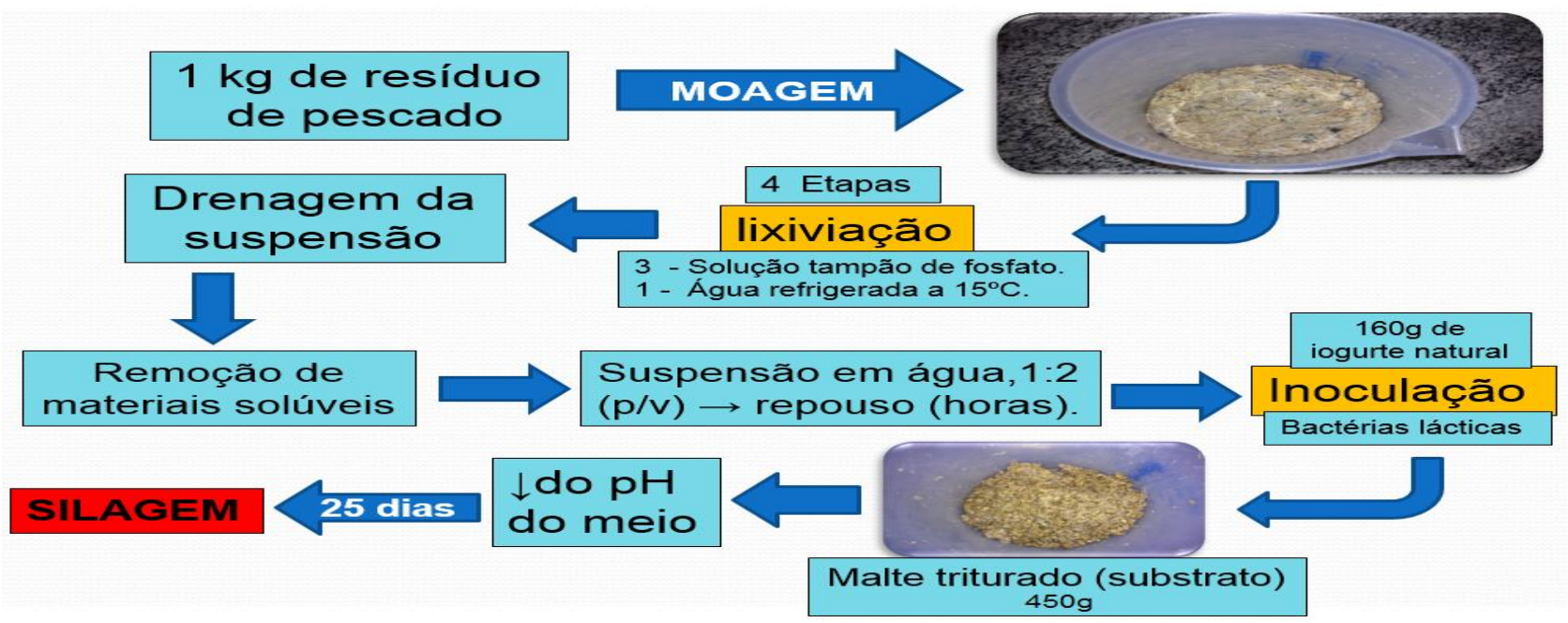

Figura 1 - Fluxograma do processo de produção da silagem de pescado.

\subsection{Unidades de Secagem (Secador de Bandeja e Liofilizador)}

A estufa de secagem utilizada para a secagem em bandeja foi da marca Nova Ética®, série 400. A secagem da silagem de pescado, ocorreu em duas diferentes temperaturas 50 e $60^{\circ} \mathrm{C}$, utilizando três bandejas de aço inox, com dimensões de $10 \mathrm{x} 10 \mathrm{x} 1 \mathrm{~cm}$ (largura, comprimento e altura, respectivamente) a partir da aplicação de um planejamento experimental fatorial do tipo $2^{2}$. Para os ensaios de secagem, inicialmente foram pesadas e taradas as bandejas, juntamente com as folhas de alumínio (usadas para revestir a parte interna das bandejas), em seguida foi adicionada a silagem em 


\section{9 a 22 de outubro de 2014 \\ Florianópolis/SC}

cada bandeja, que depois foram colocadas ao mesmo tempo na estufa de secagem, considerando a temperatura e carga de silagem. As bandejas foram retiradas sistematicamente para pesagem, durante toda a secagem, com intervalos de tempo de 20 minutos. O liofilizador utilizado para a secagem da silagem de pescado foi o da marca Liotop® modelo L202.

\subsection{Caracterização físico-química e nutricional da silagem de pescado}

Foram realizadas análises de caracterização na silagem de pescado in natura antes e após a secagem, compreendendo a determinação de proteína, lipídios, umidade, cinzas, fibras e açúcares totais. O teor de proteínas foi determinado a partir do método de Biureto, pela comparação com albumina bovina (padrão de proteína) proposto por Reigler (1914). Na determinação de fibra da silagem de pescado in natura utilizou-se o método da AOAC (2000). A determinação de lipídeos (utilizando Soxhlet), o teor de umidade inicial da silagem de pescado, teor de cinzas, bem como a determinação de $\mathrm{pH}$ e acidez titulável, foram estabelecidos de acordo com os métodos de análise do Instituto Adolfo Lutz (1985). O teor de açúcares totais foi determinado pelo método Somogy-Nelson.

\section{RESULTADOS E DISCUSSÕES}

\subsection{Caracterização da Matéria-prima}

Composição centesimal: A composição centesimal da silagem de pescado antes e após o processo de secagem foi determinada, no laboratório de Análises de Alimentos do Instituto de Ciências Exatas e da Terra, da Universidade Federal de Mato Grosso. Na Tabela 1 se encontram os valores obtidos na composição centesimal da silagem de pescado in natura, onde os resultados das análises foram expressos através da média da triplicata e desvio padrão.

Tabela 1 - Composição centesimal da silagem de pescado in natura

\begin{tabular}{|c|c|}
\hline Componentes & Matéria Úmida $(\mathrm{g} / 100 \mathrm{~g})$ \\
\hline Umidade & $76,65 \pm 0,03$ \\
\hline Proteína & $18,13 \pm 0,64$ \\
\hline Lipídeos & $1,22 \pm 0,10$ \\
\hline Cinzas & $1,12 \pm 0,01$ \\
\hline Fibra bruta & $2,18 \pm 0,08$ \\
\hline Açúcares totais & $0,10 \pm 0,01$ \\
\hline
\end{tabular}

Considerando que a composição, o valor nutritivo e o rendimento final da silagem dependem principalmente do tipo de resíduo utilizado para sua fabricação, bem como o tipo de substrato e as características do inoculo bacteriano (Giulietti, 1995), tem-se que a composição centesimal da silagem de pescado em relação a outros autores, que trabalharam com silagem de tilápia, não foram discrepantes para umidade, proteína bruta, gordura e cinzas, sendo respectivamente: 77,0, 19,0, 2,0 e 1,90 (Akande, 1989) e 77,5-79,0; 19,2 - 18,40, 2,2 - 1,90 - 1,11 a 1,08 (Marchi, 1997). Para umidade e proteína, o valores encontrados foram próximos da faixa de umidade (70 a 74 g/100g, 16 a 19 


\section{9 a 22 de outubro de 2014 \\ Florianópolis/SC}

g/100g, umidade e proteína, respectivamente) descrita por Carvajal (1998). A quantidade de lipídeos na silagem de pescado apresentou-se pouco menor do que o teor de lipídeos encontrado por Deamici \& Oliveira (2011), cerca de $1,43 \pm 02$. O teor de fibras encontrado pode ser atribuído ao malte triturado remanescente, utilizado como substrato para fermentação microbiológica. $\mathrm{O}$ teor de cinzas obtido apresentou-se semelhante a média $(1,17 \pm 0,23)$ encontrada por Arruda et al., (2009).

Determinações físico-químicas: o tempo de fermentação da silagem compreendeu 25 dias, apresentando variações de $\mathrm{pH}$ para esse período. A Tabela 2 apresenta os parâmetros físicoquímicos das amostras de silagem de pescado. $\mathrm{O} \mathrm{pH}$ final da silagem de pescado $(4,44 \pm 0,09)$, se apresentou próximo ao $\mathrm{pH}$ descrito como estável para silagens de pescado, que deve ser inferior a 4,5 (Bello, 2004).

Tabela 2 - Parâmetros físico-químicos das amostras de silagem de pescado

\begin{tabular}{|c|c|c|c|c|c|c|c|c|}
\hline \multirow{3}{*}{ Parâmetros } & \multicolumn{7}{|c|}{ Amostras } \\
\cline { 2 - 9 } & \multicolumn{2}{|c|}{ Seca $50^{\circ} \mathrm{C}$} & \multicolumn{2}{|c|}{ Seca $60^{\circ} \mathrm{C}$} & \multicolumn{2}{c|}{ Liofilizada } & \multicolumn{2}{c|}{ in natura } \\
\cline { 2 - 9 } & & $* \mathrm{CV}(\%)$ & & $* \mathrm{CV}(\%)$ & & $* \mathrm{CV}(\%)$ & $* \mathrm{CV}(\%)$ \\
\hline $\mathrm{pH}$ & $4,53 \pm 0,09$ & 2,14 & $4,58 \pm 0,16$ & 3,60 & $4,52 \pm 0,09$ & 2,01 & ---- & --- \\
\hline Acid. Titulável & $6,90 \pm 0,12$ & 1,72 & $8,01 \pm 0,21$ & 2,64 & $10,62 \pm 0,52$ & 4,80 & $10,95 \pm 0,87$ & 7,95 \\
\hline
\end{tabular}

*Coeficiente de Variação

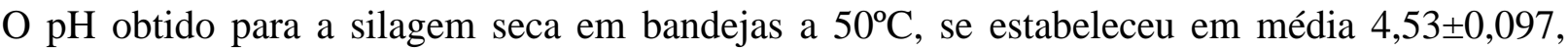
sendo levemente acima da média encontrada para a silagem in natura no último dia de fermentação $(4,44 \pm 0,09)$, já a acidez titulável $(6,90 \pm 0,12)$ se estabeleceu acima do encontrado por Vidotti \&

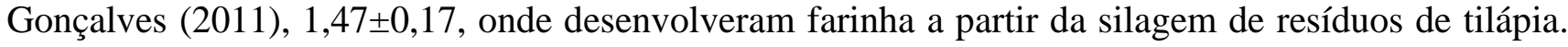
Essa discrepância, pode ser atribuída à fermentação ácida utilizada na obtenção da silagem, diferentemente da fermentação por ação microbiana empregada no presente trabalho.

Análise Estatística: A tabela 3 apresenta as respostas encontradas para os teores de proteínas, lipídeos, resíduo mineral fixo (cinzas) e açúcares totais após os processos de secagem em bandeja, da silagem de resíduos de pescado, em diferentes temperaturas e cargas de silagem.

Tabela 3 - Dados de proteínas, lipídeos, cinzas e açúcares totais, a partir do planejamento experimental do tipo $2^{2}$

\begin{tabular}{|c|c|c|c|c|c|}
\hline \multirow{2}{*}{ Temperatura $\left({ }^{\circ} \mathrm{C}\right)$} & \multirow{2}{*}{ Carga de Silagem $(\mathrm{g})$} & \multicolumn{4}{|c|}{ Resposta } \\
\cline { 3 - 5 } & & Proteína* $^{*}$ & Lipídeos* & Cinzas* & Açúcares Totais* \\
\hline-1 & -1 & 75,76 & 6,07 & 6,07 & 0,47 \\
\hline+1 & -1 & 69,63 & 5,96 & 5,96 & 0,53 \\
\hline-1 & +1 & 75,17 & 6,11 & 6,11 & 0,50 \\
\hline+1 & +1 & 67,59 & 5,90 & 5,50 & 0,41 \\
\hline-1 & -1 & 75,85 & 6,04 & 6,14 & 0,49 \\
\hline+1 & -1 & 71,24 & 5,97 & 5,57 & 0,54 \\
\hline-1 & +1 & 76,68 & 6,20 & 6,20 & 0,49 \\
\hline+1 & +1 & 70,79 & 5,89 & 5,79 & 0,43 \\
\hline-1 & -1 & 76,17 & 6,03 & 6,03 & 0,48 \\
\hline
\end{tabular}




\begin{tabular}{|c|c|c|c|c|c|}
\hline+1 & -1 & 69,79 & 6,00 & 6,00 & 0,53 \\
\hline-1 & +1 & 76,31 & 6,12 & 6,12 & 0,51 \\
\hline+1 & +1 & 71,51 & 5,94 & 5,94 & 0,41 \\
\hline
\end{tabular}

*g/100g de amostra seca

Analisando a Figura 2-a para proteína, percebe-se que o melhor parâmetro de operação independentemente da carga de silagem, é quando se utiliza o ponto mínimo de temperatura, $(-1)$ ou $50^{\circ} \mathrm{C}$, sendo essa temperatura a de maior significância no processo, nas diferentes cargas de silagem ( 48,8g a 97,5g). Avaliando a Figura 2-b percebe-se que a melhor faixa de operação para lipídeos é quando se utiliza o ponto mínimo de temperatura e o ponto máximo da carga de silagem $\left(50^{\circ} \mathrm{C}(-1)\right.$ e $\sim 97,5 \mathrm{~g}(+1)$ ). Considerando a Figura 2-c percebe-se que o melhor modelo, de primeira ordem, relacionado à condição experimental para cinzas é com a temperatura de $60^{\circ} \mathrm{C}(+1)$ junto ao ponto máximo de carga de silagem de pescado, $\sim 97,5 \mathrm{~g}(+1)$, ou seja, para a secagem a temperatura de $60^{\circ} \mathrm{C}$ foi o fator de maior significância. Analisando as curvas de contorno da Figura 2-d, percebe-se que o melhor modelo é quando se utiliza a temperatura de $\sim 54^{\circ} \mathrm{C}(-0,2)$ junto ao uma carga de silagem de 60g $(-0,6)$, ou seja, a interação entre temperatura e carga de silagem foi o fator de maior significância na obtenção da variável resposta. Entretanto ambos os fatores isolados, foram relevantes para o teor de açúcares totais.

(a)

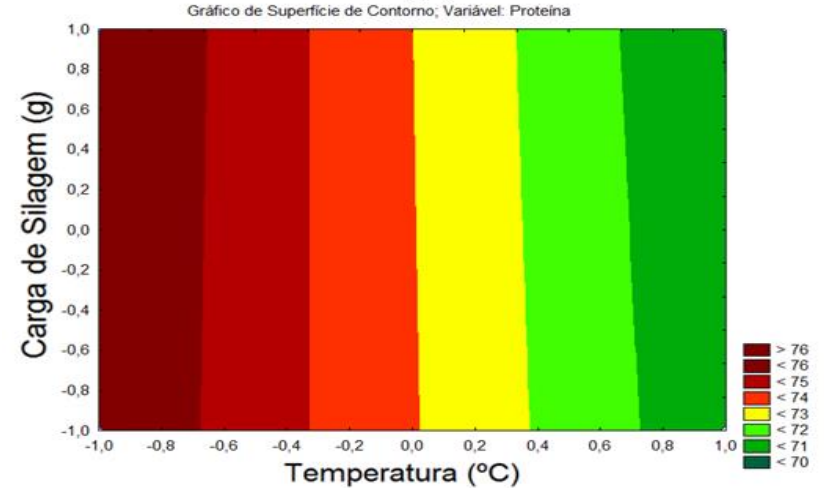

(c)

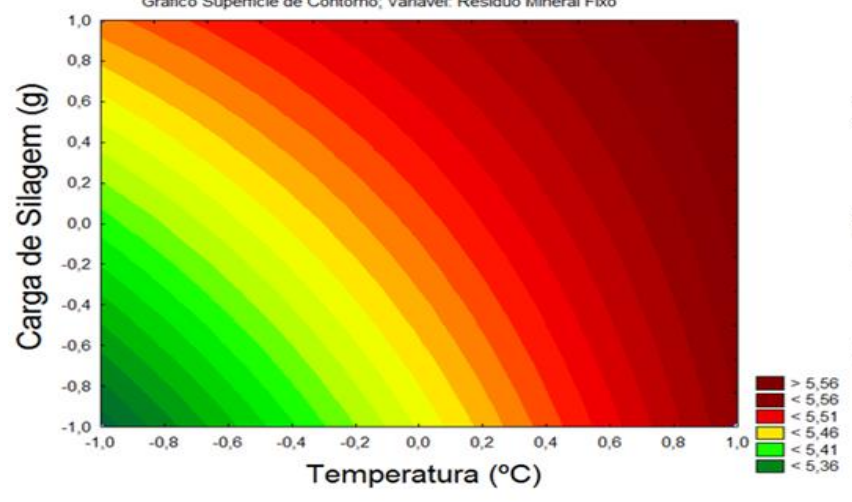

(b)



(d)

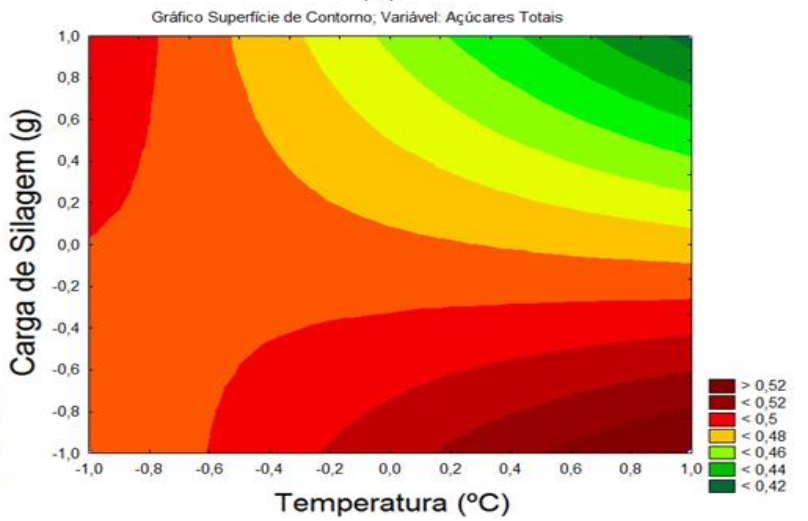

Figura 2 - Curvas de Contorno correspondente à superfície de resposta de proteínas (a), lipídeos (b), cinzas (c) e açúcares totais (d) de silagem de pescado após o processo de secagem em bandejas. 
Estudo das Características da Silagem de Pescado Liofilizada: o teor de proteínas da silagem liofilizada $(72,81 \pm 0,64)$ foi maior em comparação as amostras secas em bandejas em 50 e $60^{\circ} \mathrm{C}$

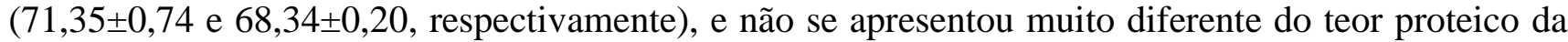
silagem in natura, isso se deve ao fato de que no processo de liofilização resulta na formação de misturas eutéticas (temperatura de fusão dos componentes da mistura se torna a mesma), promovendo mínimas modificações na composição do teor proteico (Baruffaldi \& Oliveira, 1998). Para lipídeos, $5,37 \pm 0,18 \mathrm{~g} / 100 \mathrm{~g}$, houve uma concentração de sua quantidade, devido à remoção de umidade, porém esse teor foi menor do que a secagem em bandeja $\left(50^{\circ} \mathrm{C}\right.$ e $\left.60^{\circ} \mathrm{C}\right)$, essa diminuição foi devido à conservação da textura da silagem liofilizada, com pouco encolhimento e nenhuma formação de crosta na superfície, formando uma estrutura porosa que promoveu a deterioração oxidativa de parte desses lipídeos (Fellows, 2006). O teor de cinzas resultante do processo de liofilização $(4,89 \pm 0,40$ $\mathrm{g} / 100 \mathrm{~g}$ ) foi menor do que a secagem em bandeja, indicando que a liofilização promoveu uma menor liberação de minerais na matriz orgânica. O teor de açúcares totais presente nas amostras liofilizadas $(0,12 \pm 0,01 \mathrm{~g} / 100 \mathrm{~g})$ foi maior que o presente nas amostras secas em bandejas, indicando que o processo não permitiu perdas e nem reações de escurecimento não enzimático (Reação de Maillard).

\subsection{Cinética de Secagem da Silagem de Pescado}

Caracterização da Secagem: as Figuras 3-a, 3-b, 3-c e 3-d apresentam o adimensional de umidade $\left(\mathrm{X} / \mathrm{X}_{0}\right)$ em função do tempo (min), no intuito de estabelecer os períodos de taxa constante e decrescente durante a secagem da silagem de pescado.

(a)

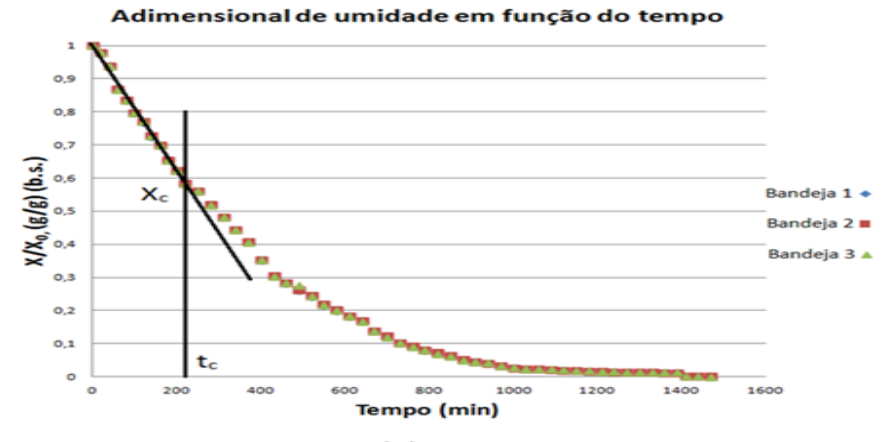

(c)



(b)

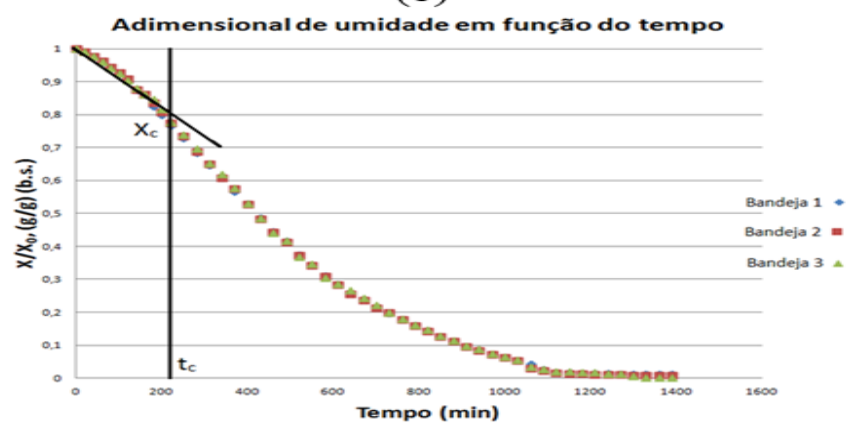

(d)

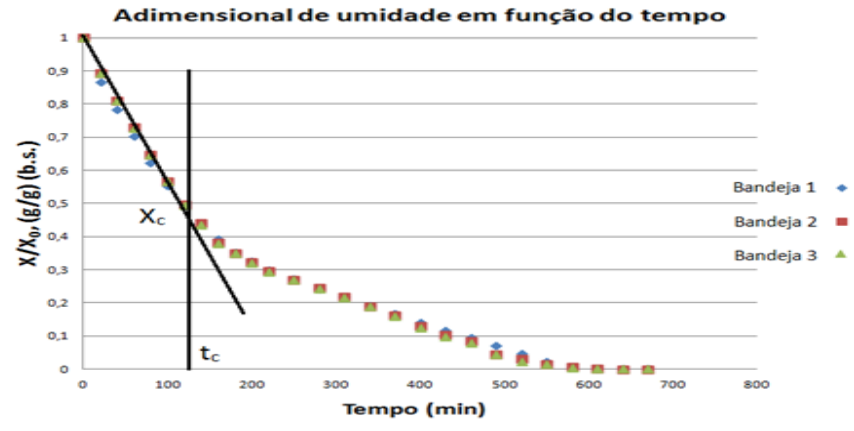

Figura 3 - Curva do adimensional de umidade em função do tempo: (a) silagem com carga de $\sim 97,5 \mathrm{~g} \mathrm{seca} \mathrm{em} 50^{\circ} \mathrm{C}$, (b) silagem com carga de $\sim 97,5 \mathrm{~g}$ seca em $60^{\circ} \mathrm{C}$, (c) silagem com carga de $\sim 48,8 \mathrm{~g}$ seca em $50^{\circ} \mathrm{C}$ e $(\mathrm{d})$ silagem com carga de $\sim 48,8 \mathrm{~g}$ seca em $60^{\circ} \mathrm{C}$. 


\section{9 a 22 de outubro de 2014 \\ Florianópolis/SC}

Pode-se observar, em todos os gráficos da Figuras 3, a existência de dois períodos distintos durante a secagem: o período de taxa constante, antes do ponto de tempo crítico $\left(\mathrm{t}_{\mathrm{c}}\right)$ e o período de taxa decrescente, após o $t_{c}$ (início da inflexão da curva de secagem). A partir da relação entre o adimensional de umidade e tempo $(\mathrm{t})$ e o período de taxa decrescente (primeira fase e segunda fase) pôde-se estabelecer os valores médios da umidade crítica $\left(\mathrm{X}_{\mathrm{C}}\right)$, da taxa constante de umidade $\left(\mathrm{N}_{\mathrm{C}}\right)$, tempo da taxa constante $\left(\mathrm{t}_{\mathrm{c}}\right)$ e a umidade de equilíbrio $\left(\mathrm{X}_{\mathrm{E}}\right)$ para cada triplicata de experimento, conforme a Tabela 4.

Tabela 4 - Caracterização da secagem da silagem de pescado

\begin{tabular}{|c|c|c|c|c|c|c|c|c|}
\hline $\begin{array}{c}\text { Secagem } \\
\begin{array}{c}\text { Silagem de } \\
\text { Pescado }\end{array}\end{array}$ & $\begin{array}{c}\mathrm{X}_{\mathrm{C}} \\
(\mathrm{g} / \mathrm{g})\end{array}$ & $\begin{array}{c}\mathrm{N}_{\mathrm{C}} \\
(\mathrm{g} / \mathrm{g} * \mathrm{~min})\end{array}$ & $\begin{array}{c}\mathrm{t}_{\mathrm{C}} \\
(\mathrm{min})\end{array}$ & $\begin{array}{c}\mathrm{X}_{\mathrm{E}} \\
(\mathrm{kg} / \mathrm{kg})\end{array}$ & \multicolumn{2}{|c|}{$1^{\mathrm{a}}$ Fase } & \multicolumn{2}{|c|}{$2^{\mathrm{a}}$ Fase } \\
\cline { 6 - 10 } & & & & $\mathrm{K}$ & $\begin{array}{c}\mathrm{R}^{2} \\
\%\end{array}$ & $\begin{array}{c}\mathrm{K} \\
10^{-2 *} * \mathrm{~min}^{-1}\end{array}$ & $\begin{array}{c}\mathrm{R}^{2} \\
\%\end{array}$ \\
\hline$\sim 97,5 \mathrm{~g}$ à $50^{\circ} \mathrm{C}$ & $2,04 \pm 0,03$ & $0,002 \pm 1,42$ & 200 & 0,010 & $2,72 \pm 0,01$ & 98,20 & $4,92 \pm 0,01$ & 84,75 \\
\hline$\sim 97,5 \mathrm{~g}$ à $60^{\circ} \mathrm{C}$ & $2,54 \pm 0,02$ & $0,002 \pm 0,97$ & 220 & 0,010 & $4,34 \pm 0,01$ & 98,21 & $3,35 \pm 0,02$ & 88,26 \\
\hline$\sim 48,8 \mathrm{~g}$ à $50^{\circ} \mathrm{C}$ & $1,00 \pm 0,01$ & $0,006 \pm 1,03$ & 180 & 0,011 & $1,95 \pm 1,89$ & 81,62 & $1,91 \pm 0,02$ & 76,88 \\
\hline$\sim 48,8 \mathrm{~g}$ à $60^{\circ} \mathrm{C}$ & $1,62 \pm 0,02$ & $0,008 \pm 0,04$ & 120 & 0,011 & $3,83 \pm 0,05$ & 94,60 & $2,62 \pm 0,02$ & 91,10 \\
\hline
\end{tabular}

Observa-se a partir da Tabela 4, que na $1^{\mathrm{a}}$ fase do período da taxa decrescente, tanto para a secagem de silagem em $60^{\circ} \mathrm{C}$ com carga de $\sim 48,8 \mathrm{~g}$ como a de $\sim 97,5 \mathrm{~g}$, a constante de secagem $(\mathrm{K})$ se estabeleceu maior do que comparada ao $\mathrm{K}$ da secagem em temperatura de $50^{\circ} \mathrm{C}$ nas diferentes cargas, demonstrando, deste modo, a enorme influência que a temperatura exerce durante a secagem. Na $2^{a}$ fase, os valores de $\mathrm{K}$ foram bastante divergentes considerando as mesmas temperaturas, o que pode ser atribuído a algum desvio experimental, como a na remoção das bandejas para pesagem, durante o procedimento de secagem.

\section{CONCLUSÕES}

O desenvolvimento da silagem de pescado se estabelece como uma alternativa para a indústria pesqueira, pois dá um destino aos resíduos gerados por ela, constituindo uma opção de matéria-prima de qualidade para o desenvolvimento de produtos com alto teor agregado de nutrientes. Os resultados estatísticos para a composição centesimal da silagem, seca em 50 e $60^{\circ} \mathrm{C}$ com cargas de $\sim 48,8$ e 97,5g apresentaram respostas distintas em relação a linearidade no processo de obtenção da variável resposta. A liofilização apresentou-se como melhor opção para minimizar as perdas nutricionais durante a secagem, corroborado pela manutenção do teor médio de proteínas e açúcares totais quando comparadas às amostras in natura e as secas em bandejas. A caracterização da cinética de secagem demonstrou o comportamento do material durante a secagem, sendo que o ensaio com carga de $\sim 48,8 \mathrm{~g}$ e temperatura de $60^{\circ} \mathrm{C}$ ocorreu em um menor tempo e o parâmetro temperatura foi o que mais se destacou para obtenção da variável resposta. As curvas experimentais de secagem apresentaram os períodos de taxa constante e taxa decrescente, sendo que a secagem ocorreu em sua maior parte na região da $1^{\text {a }}$ fase da taxa decrescente. Assim, a elaboração da silagem de pescado juntamente com sua secagem para o desenvolvimento de produtos, se estabelece como um processo simples e prático que traz ganhos econômicos para indústria de processamento de pescado. 


\section{REFERÊNCIAS}

AKANDE, G. R. Technical note: Improved utilisation of stunted tilapia sp. J. of Food Sci and Tec. v. 24, p. 20-26, 1989.

AOAC - ASSOCIATION OF OFFICIAL ANALYTICAL CHEMISTS. Official methods of analysis. 15.ed. Virginia, Washington: Arlington, 1995.

BARUFFALDI, R. \& OLIVEIRA, M. N. Fundamentos de tecnologia de alimentos. São Paulo: Atheneu, 1998. 317p.

BELLO, R. A. Experiências com ensilado de pescado em Venezuela. Instituto de Ciências y Tecnologia de Alimentos. Caracas: Universidad Central de Venezuela, 2004. Disponível em: <http// www.fao.org/livestock/ aphp134/cap1.htm>. Acesso em: 20 set. 2013.

CARVAJAL, G. Fundamentos de la tecnología de ensilados. In Procesamiento de Ensilado de Pescado. ITP/JICA, XIV Curso Internacional Tecnología de Procesamiento de Productos Pesqueros. Callao - Perú. p. 1-15. 1998.

DEAMICI, K. M. \& OLIVEIRA, E. G. Obtenção de silagem ácida de pescado: avaliação da etapa de secagem. Digital Repository. UFRGS, 2011.

FELlOWS, P. J. Tecnologia do processamento de alimentos: Princípios e prática. Vol 1. $2^{\mathrm{a}}$ Ed. Porto Alegre: Editora Artmed, Cap 15. 602p. 2006.

GIULIETTI, N. \& ASSUMPÇÃO R. Indústria pesqueira no Brasil. Revista Agricultura em São Paulo. v.2, n.42, p.95-127, 1995.

INSTITUTO ADOLFO LUTZ - IAL. Métodos físico-químicos para análise de alimentos. Coordenadores Odair Zenebon, Neus Sadocco Pascuet e Paulo Tiglea - São Paulo: Instituto Adolfo Lutz, 117p. 1985.

MARCHI, J. F. Desenvolvimento e avaliação de produtos à base de surimi produzidos a partir de tilápia nilótica, Oreochromis niloticus L. (Dissertação). Ciência e Tecnologia de Alimentos, Universidade Federal de Viçosa, 1997.

MORAIS, C. \& MARTINS, J. Considerações sobre o aproveitamento de sobras da industrialização de pescado na elaboração de produtos alimentícios. Bol. ITAL, v.18, p. 253-81, 198.

REIGLER, E. Eine Kolorimetrische Bestimmungs methods des Eiweisses. Z Anal Chem; 53:242-5, 1914.

VENUGOPAL, V. \& SHAHIDI, F. Value-added products from underutilized fish species. Crit. Rev. in Food Sci. and Nut., v.35, n.5, p.431- 453, 1995.

VIDOTTI R.M. \& GONÇALVES, G. S. Produção e Caracterização de Silagem, Farinha e Óleo de Tilápia e sua Utilização na Alimentação Animal. 2011. Disponibilizado em: <www.pesca.sp.gov.br>. Acesso em 03 out. de 2013. 